\title{
Survival and long-term outcomes after concomitant mitral and aortic valve replacement in patients with rheumatic heart disease
}

\author{
Vivek Velayudhan Pillai ${ }^{1}$ (D) $\cdot$ Renjith Sreekantan ${ }^{1} \cdot$ Nayana Nemani $^{2} \cdot$ Jayakumar Karunakaran $^{1}$ \\ Received: 15 April 2020 / Revised: 13 July 2020 / Accepted: 17 July 2020 / Published online: 27 August 2020 \\ (C) Indian Association of Cardiovascular-Thoracic Surgeons 2020
}

\begin{abstract}
Introduction Double valve replacement (DVR) with a mechanical prosthesis is associated with a higher risk of mortality. We planned to study the survival rate, early and late mortality and major adverse cardiac and cerebrovascular events (MACCE) in patients undergoing DVR for rheumatic heart disease, with various generations of prosthetic valves ranging from ball in cage to bileaflet prosthesis and tilting disc valves.

Materials and methodology We followed up 277 patients with rheumatic heart disease who underwent DVR between August 1999 and November 2009, retrospectively, at Sree Chitra Tirunal Institute for Medical Sciences and Technology, Thiruvananthapuram. Two hundred and fifty-nine patients were followed up for a minimum period of 10 years, and the follow-up period varied between 10 and 20 years. Eighteen patients were lost to follow-up after the surgery and could not be contacted. Their data was included till the time they appeared for follow-up last, for survival analysis. Survival analysis was carried out using the life table method to calculate the freedom from reoperation, survival rates and freedom from MACCE at 1 year, 5 years and 10 years post-DVR.

Results The median duration of hospital stay was 8 days. The number of patients with stroke was $11(4.26 \%), 21(8.7 \%)$ and 29 $(12 \%)$ at the end of 1 year, 5 years, and 10 years, respectively. A total of $5(2 \%)$ patients underwent reoperation by the end of 10 years. Seven patients died either in hospital or in the first 30 days following operation, making the early mortality $2.5 \%$. At the end of 1 year, a total of 16 patients $(5.8 \%$ ) died. The mortality at the end of 5 years was $6.8 \%$ (19 patients), and at the end of 10 years, it was $7.2 \%$ (20 patients). The survival rate of the study population was $94.9 \%, 93.02 \%$ and $93.02 \%$ at the completion of 1 year, 5 years and 10 years, respectively. The freedom from MACCE was $93.8 \%, 88.6 \%$ and $85 \%$ at 1 year, 5 years and 10 years, respectively. The freedom from re-operation was $98 \%$ at 10 years. Kaplan-Meier analysis showed an overall survival time of 226.3 months in the entire study population. The mean survival time in males was 227.5 months and in females was 206.3 months, with no statistically significant difference between the two. Univariate logistic regression analysis revealed an association with mortality when DVR was combined with concomitant tricuspid valve repair procedures, with an odds ratio of 4.5 ( $p$ value 0.005 ). Multivariate logistic regression analysis also showed an association with mortality when tricuspid valve procedures were combined with DVR with an odds ratio of 5.25 ( $p$ value 0.003 ).

Conclusion The operative mortality and morbidity for DVR have been significantly reduced with advancements in operative techniques, myocardial preservation and postoperative care. Patients can have an improved functional status following surgery, with good rates of freedom from re-operation and MACCE.
\end{abstract}

Keywords Double valve replacement $\cdot$ Concomitant mitral and aortic valve replacement survival $\cdot$ Long-term outcomes $\cdot$ Survival rates

Vivek Velayudhan Pillai

drvivekpillai@yahoo.co.in

1 Department of Cardiovascular and Thoracic Surgery, Sree Chitra Tirunal Institute for Medical Sciences and Technology, Trivandrum 695011, India

2 Department of Cardiothoracic and Vascular Anaesthesia, Sree Chitra Tirunal Institute for Medical Sciences and Technology, Trivandrum, India

\section{Background}

Valvular heart disease of rheumatic origin plagues developing nations, and multiple-valve involvement is not uncommon when the patients are symptomatic and lesions, severe. We studied the outcome and survival rate following doublevalve replacement (DVR) in patients with rheumatic heart disease (RHD), in a large tertiary centre in south India. 


\section{Introduction}

RHD accounts for majority of the cases with valvular heart disease (VHD) in patients belonging to developing nations. Most of these patients present for intervention when the disease progression makes them symptomatic and also when there is multiple valvular valve involvement.

DVR with a mechanical prosthesis is associated with a higher risk of mortality. The data based on which this risk has been assigned was initially derived from studies performed in the 1980s when older-generation mechanical prostheses, like the Bjork-Shiley mechanical heart valve (Shiley Corp, Irvine, CA) and the Medtronic Hall valve (Medtronic, Inc., Minneapolis, $\mathrm{MN}$ ), were in use and the high mortality for DVR persisted in subsequent studies with the newergeneration valves as well [1-3]. The late complications seen post valve replacement surgery are usually multifactorial in aetiology and depend on factors like the patient's functional status, rhythm, prosthetic valve type and anticoagulation. We planned to study the survival rate, early and late mortality and major adverse cardiac and cerebrovascular events (MACCE) in patients undergoing DVR with various generations of prosthetic valves, ranging from ball-in-cage to bileaflet prostheses and tilting disc valves and the factors affecting the above parameters.

\section{Materials and methodology}

The aim of the study was to find out the long-term survival rates and the incidence of MACCE after DVR in patients with RHD. We followed up 277 patients who underwent DVR between August 1999 and November 2009 retrospectively, at Sree Chitra Tirunal Institute for Medical Sciences and Technology, Thiruvananthapuram. Data was collected from hospital records and via telephonic interviews. All patients with RHD who underwent DVR during the mentioned time period were included in the study. Patients with VHD of other aetiologies were excluded. Patients who underwent coronary artery bypass grafting $(\mathrm{CABG})$ along with DVR and those who underwent valve replacement surgery prior to the study period and came for a redo surgery of the valve were excluded. Two hundred and fifty-nine patients were followed up for a minimum period of 10 years, and the follow-up period varied between 10 and 20 years. Eighteen patients were lost to follow-up after the surgery and could not be contacted. Their data was included for survival analysis till the time they appeared for follow-up last.

\section{Operative procedure}

All patients were operated on through a midline sternotomy. A roller pump with crystalloid prime was used, and aorto- bicaval bypass was instituted for all the patients. Antegrade cardioplegia was administered through the aortic root, and ostial cardioplegia was chosen in patients with aortic regurgitation. Standard techniques were used and the valves were replaced using interrupted sutures. Moderate hypothermia ( 28 to $32{ }^{\circ} \mathrm{C}$ ) was used, and cold-blood cardioplegia with St Thomas II solution was employed for arresting the heart in all the cases.

Statistical methods Descriptive analysis was carried out by mean and standard deviation for quantitative variables, and frequency and proportion for categorical variables. Data was also represented using appropriate figures like bar diagrams, pie charts and box plots.

The association between categorical explanatory variables and quantitative outcome was assessed by comparing the mean values. The mean differences along with their $95 \%$ confidence interval (CI) were calculated. The mean survival time in the entire study group was computed, and the difference in the mean survival between males and females was compared using the log rank test (Mantel-Cox).

$P$ value $<0.05$ was considered statistically significant. Survival analysis was carried out using the life table method, and Kaplan-Meier curves were used to calculate the freedom from reoperation, survival rates and freedom MACCE at the end of 1 year, 5 years and, 10 years. IBM SPSS version 22 was used for statistical analysis. The institutional technical advisory committee and institutional ethics committee clearances were obtained before commencing the study.

\section{Results}

A total of 277 patients with VHD of rheumatic aetiology who underwent DVR between 1999 and 2009 were included in this study.

Demographic parameters The mean age of the patients who were part of the study was 37 years. The oldest patient was 62 years old and the youngest was 10 years old. A hundred and fifty-five of the patients were male (55.9\%) and 122 were female $(44.1 \%)$ (Table 1, patient characteristics).

Preoperative status A hundred and fifty-two patients (54.8\%) had New York Heart Association (NYHA) functional class II symptoms, 118 patients $(42.6 \%)$ had class III symptoms and 7 patients $(2.5 \%)$ belonged to NYHA class IV category. The number of patients with VHD who were in atrial fibrillation preoperatively was 98 (35\%) (Table 1, patient characteristics).

Majority of the patients did not have any co-morbid illness (88.4\%). Twelve patients had history of cerebrovascular accidents, six patients had diabetes mellitus, two patients had hypertension, three patients had chronic kidney disease, and two 
patients had a prior history of hepatitis B virus infection. Closed mitral valvotomy (CMV) was performed in 28 patients $(10.11 \%)$, and balloon mitral valvotomy (BMV) was done in 15 patients $(5.42 \%)$.

Preoperative ejection fraction Preoperative ejection fraction (EF) varied from 35 to $89 \%$, with two patients having moderate left ventricular dysfunction and 18 patients having mild left ventricular dysfunction. Two hundred and fifty-five patients $(92 \%)$ had good left ventricular systolic function (Table 1, patient characteristics).

Valve lesions Mitral stenosis was present in $88.4 \%$ of the patients, with 94 (33.9\%) of them having moderate stenosis of the mitral valve and 151 (54.5\%) having severe stenosis. Mitral regurgitation was significant on echocardiography in only $54.5 \%$ of the patients. Severe mitral regurgitation was seen in 67 patients (24.2\%), and moderate mitral regurgitation was present in 84 patients (30.3\%), making stenosis the commoner lesion when the mitral valve was involved.

Severe aortic stenosis was present preoperatively in 104 patients $(37.55 \%)$, and moderate stenosis of the aortic valve was seen in 112 patients $(40.43 \%)$. Aortic regurgitation was

Table 1 Patient characteristics

\begin{tabular}{|c|c|}
\hline Age (years) & $37.02 \pm 10.76$ \\
\hline \multicolumn{2}{|l|}{ Gender } \\
\hline Male & $155(55.96 \%)$ \\
\hline Female & $122(44.04 \%)$ \\
\hline \multicolumn{2}{|l|}{ Rhythm } \\
\hline Sinus & $179(64.62 \%)$ \\
\hline Atrial fibrillation & $98(35.38 \%)$ \\
\hline \multicolumn{2}{|l|}{ Functional class } \\
\hline Class 2 & $152(54.87 \%)$ \\
\hline Class 3 & $118(42.60 \%)$ \\
\hline Class 4 & $7(2.53 \%)$ \\
\hline \multicolumn{2}{|l|}{ Comorbidities } \\
\hline Diabetes mellitus & $6(2.3 \%)$ \\
\hline Hypertension & $2(0.8 \%)$ \\
\hline Hepatitis B & $2(0.8 \%)$ \\
\hline Chronic kidney disease & $3(1.2 \%)$ \\
\hline Cerebrovascular accident & $12(4.3 \%)$ \\
\hline No comorbidities & $245(88.4 \%)$ \\
\hline BMV & $15(5.42 \%)$ \\
\hline CMV & $28(10.11 \%)$ \\
\hline \multicolumn{2}{|c|}{ Preoperative ejection fraction (EF) } \\
\hline Normal & $255(92 \%)$ \\
\hline Mild dysfunction & $18(6.4 \%)$ \\
\hline Moderate dysfunction & $2(0.72 \%)$ \\
\hline
\end{tabular}

$B M V$ balloon mitral valvotomy, $C M V$ closed mitral valvotomy severe in 78 patients $(28.2 \%)$ and moderate in 136 patients $(49.1 \%)$.

Right ventricular function was normal in 275 patients (99\%), whereas 2 patients had mild right ventricular dysfunction.

Prosthesis type and size The sizes of the aortic prostheses used ranged from 17 to 29 , with a majority of patients receiving a prosthesis of size 21 or 23 . A hundred and one patients $(36.46 \%)$ had a prosthetic aortic valve of size 21 , and sixtyeight patients $(24.55 \%)$ had a prosthesis of size 23 implanted in the aortic position.

The most commonly used aortic valve prosthesis was Chitra heart valve prosthesis (TTK CHVP, TTK Healthcare Limited, Chennai, Tamil Nadu), with 204 patients (73.65\%) having received them. Medtronic Hall valve (Medtronic, Inc., Minneapolis, MN) prosthesis was implanted in 37 patients, St. Jude Medical ${ }^{\circledR}$ Mechanical Heart Valve (SJM, St. Jude Medical Inc., Minneapolis, MN) prosthesis in 32 patients and Starr-Edwards valve (Edwards Lifesciences, Irvine, CA) prosthesis and bioprosthetic valve in 2 patients each.

The sizes of the mitral valve prostheses implanted ranged from 23 to 32 . Two patients $(0.72 \%)$ were implanted with the smaller size 23 prosthesis. Eighteen patients $(6.5 \%)$ were implanted with size 25 prosthesis; fifty-one patients (18.41\%), size $27 ; 73$ patients $(26.35 \%)$, size 28 ; 46 patients $(16.61 \%)$, size 29 ; and 51 patients $(18.41 \%)$, size 30 . The larger prostheses were implanted in 6 patients $(2.17 \%)$, size 31 , and, 23 patients $(8.3 \%)$, size 32 .

One hundred and forty-seven patients (53.07\%) received Starr-Edwards valve (Edwards Lifesciences, Irvine, CA) prosthesis whereas 72 (25.99\%) patients received Chitra heart valve prosthesis (TTK CHVP, TTK Healthcare Limited, Chennai, Tamil Nadu). Forty-five patients (16.2\%) received St. Jude Medical ${ }^{\circledR}$ Mechanical Heart Valve (SJM, St. Jude Medical Inc., Minneapolis, MN) prosthesis, 11 patients (3.97\%) received Medtronic Hall (Medtronic, Inc., Minneapolis, MN) valves, and 2 patients received bioprosthetic valves.

\section{Concomitant procedures}

\section{Tricuspid valve repair}

Twenty-eight patients underwent tricuspid valve repair along with DVR. Devega's procedure was the most common technique of repair and was used in 15 patients (5.42\%), bicuspidisation of the trileaflet was employed in 7 patients $(2.53 \%)$, commissurotomy was performed in 5 patients $(1.81 \%)$, and Kays annuloplasty was performed in 1 patient $(0.36 \%)$. 


\section{Left atrial reduction procedures}

Left atrial appendage (LAA) exclusion was performed in 29 patients $(10.47 \%)$, exclusion with left atrial (LA) plication was carried out in 28 patients $(10.11 \%)$, and LA plication alone was performed in 7 patients $(2.53 \%)$. Some of the lesser-employed techniques were Kawazoe's technique in two patients $(0.72 \%)$, Kawazoe's technique with LAA exclusion in two patients $(0.72 \%)$, and para annular reduction plasty in one patient $(0.36 \%)$.

\section{Right atrial reduction procedures}

The size of the right atrium was reduced in 2 patients $(0.72 \%)$.

\section{Hospital stay}

The median duration of hospital stay was 8 days with an interquartile range $(7,10)$.

\section{Re-operation}

Before the end of one year, three patients were re-operated on. One of the three underwent redo DVR at the end of one year in view of fungal prosthetic valve endocarditis, another underwent redo mitral valve replacement for a stuck prosthetic valve and the third patient developed paravalvular mitral regurgitation after 4 months of DVR and underwent redo mitral valve replacement, which required a subsequent re-operation (mitral valve replacement) after 6 months of the first surgery.

At 8 years, two patients underwent re-operation, one for a stuck aortic valve and the other patient for paravalvular mitral regurgitation. At the end of 10 years, a total of $5(2 \%)$ patients underwent re-operation.

\section{Mortality}

\section{Early mortality}

Seven patients died either in hospital or in the first 30 days following surgery, making the early mortality $2.5 \%$. Among the seven, four patients died of post-cardiopulmonary bypass (CPB) myocardial dysfunction with low cardiac output and multi-organ dysfunction syndrome (MODS), one developed atrioventricular (AV) groove disruption, one patient had postoperative bleeding and cardiac arrest and the last patient developed pneumonia and septicaemia in the intensive care unit.

\section{Intermediate and long-term mortality}

At the end of one year, a total of 16 patients $(5.8 \%)$ died. The mortality at the end of 5 years was $6.8 \%$ (19 patients), and at the end of 10 years, the mortality rate was $7.2 \%$ (20 patients) (Table 2).

\section{Functional class}

The NYHA functional class at the end of 10 years improved to class I in 178 patients $(74.5 \%)$. NYHA class II symptoms were reported by 56 patients $(23.4 \%)$, and 5 patients $(2.1 \%)$ had NYHA class III symptoms.

\section{Valve-related complications}

\section{Infective endocarditis}

The rate of infective endocarditis was 0.36 per 100 patient years. A total of twelve patients developed prosthetic valve endocarditis (PVE) and seven of them died. All the seven patients had early bacterial PVE (within 12 months of surgery). Among the remaining five, three patients developed late bacterial PVE and two patients developed late fungal PVE (one underwent re-do DVR). The other patients were medically managed. One of the patients with fungal PVE had a size 21 Chitra heart valve prosthesis (TTK CHVP) in aortic position and a size 28 Starr-Edwards valve in mitral position. The other patient had a size 25 TTK CHVP in aortic position and a size 29 TTK CHVP in mitral position. There was no previous history of endocarditis in any of these patients.

\section{Thromboembolic complications}

\section{Stroke}

Three patients $(1.11 \%)$ developed stroke in the immediate post-operative period. All of them developed left-sided weakness. The number of patients with stroke was 11 (4.26\%), 21 $(8.7 \%)$ and $29(12 \%)$ at the end of 1 year, 5 years and 10 years respectively. The rate of stroke was 0.63 per 100 patient years.

\section{Valve and peripheral thrombosis}

A total of three patients developed prosthetic valve thrombosis during the study period. One of them had it within one year of surgery and underwent re-do mitral valve replacement (MVR); the second patient developed stuck valve due to poor compliance with anticoagulation 6 years after DVR and was thrombolysed. The third patient developed thrombosis of the aortic prosthesis after 8 years of DVR and underwent re-do aortic valve replacement (AVR). A patient developed popliteal artery thrombosis after 11 years of DVR, and it required an an embolectomy. 
Table 2 Causes of mortality within 10 years in the study population

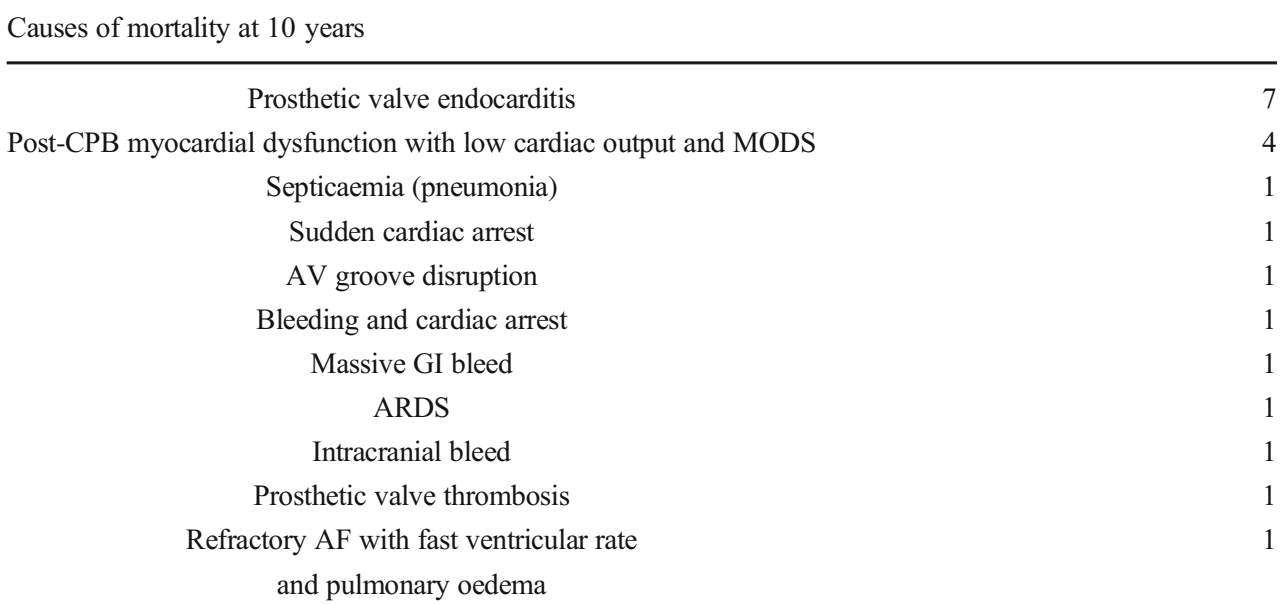

Post-CPB myocardial dysfunction with low cardiac output and MODS 4

Septicaemia (pneumonia)

Sudden cardiac arrest

AV groove disruption

Bleeding and cardiac arrest

Massive GI bleed

ARDS

Intracranial bleed

Prosthetic valve thrombosis

Refractory AF with fast ventricular rate and pulmonary oedema

$C P B$ cardiopulmonary bypass, $M O D S$ multi-organ dysfunction syndrome, $A V$ atrioventricular, $G I$ gastrointestinal, $A R D S$ acute respiratory distress syndrome, $A F$ atrial fibrillation

\section{Anticoagulation-related haemorrhagic complications}

One patient developed intracranial bleed after 1 year of DVR, and it led to mortality. Another patient had a massive gastrointestinal (GI) bleed after 10 years of surgery and succumbed to it.

\section{Other complications}

Two patients developed heart block and required pacemaker implantation, one on the 11th post-operative day and the other after 1 month from surgery. There was one case of pericardial effusion which was drained.

\section{Survival analysis}

The survival rates of the study population were $94.9 \%$, $93.02 \%$ and $93.02 \%$ at 1 year, 5 years and 10 years respectively. (Fig. 1, life table analysis of the overall survival rate of the study population).

The freedom from MACCE rate was 93.8\%, 88.6\% and $85 \%$ at 1 year, 5 years and 10 years respectively (Fig. 2, life table analysis of MACCE occurrence rate among the study population).

The freedom from re-operation was $98 \%$ at 10 years (Fig. 3, life table analysis of re-operation in the study population).

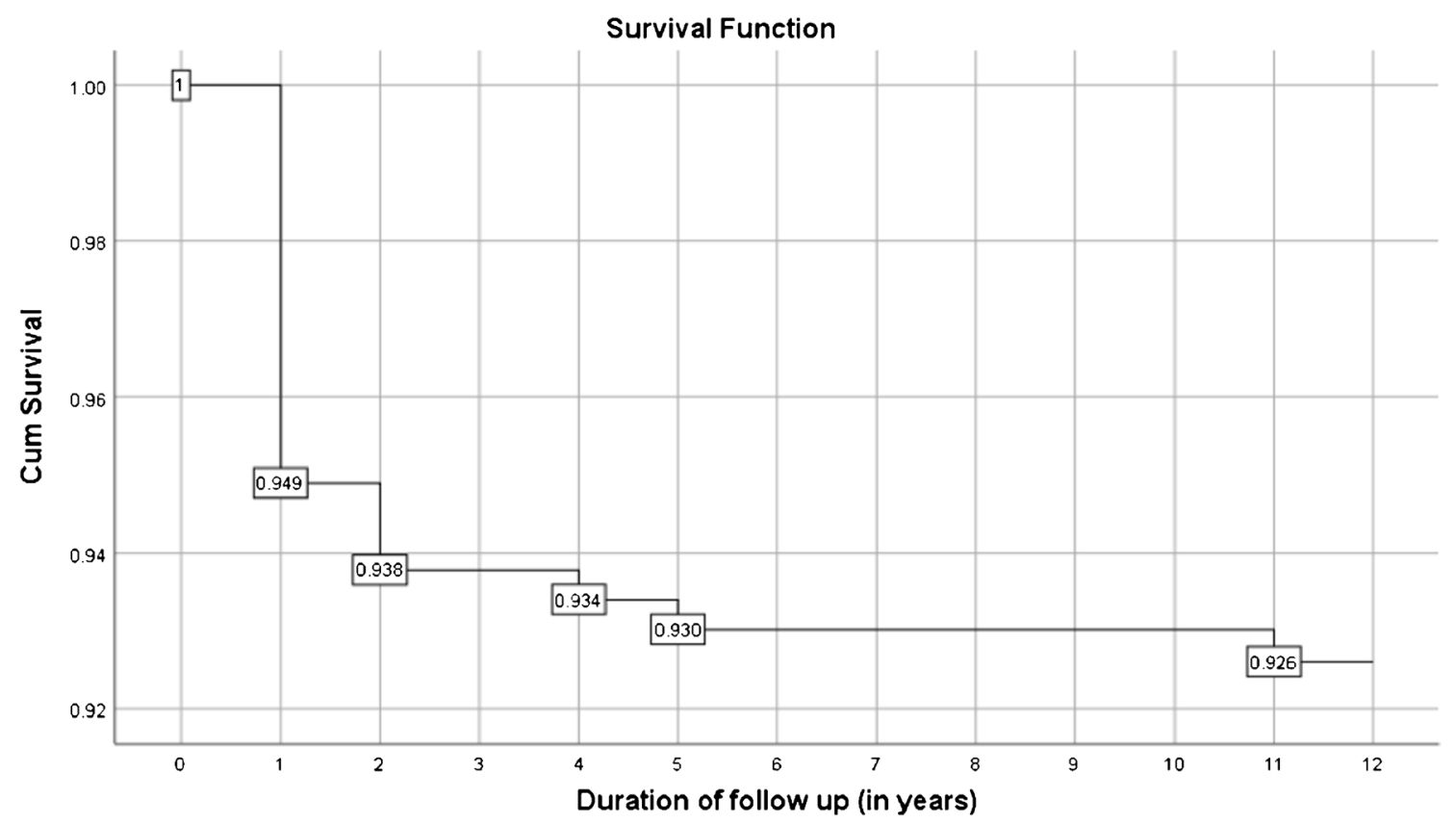

Fig. 1 Life table analysis of the overall survival rate in the study population 


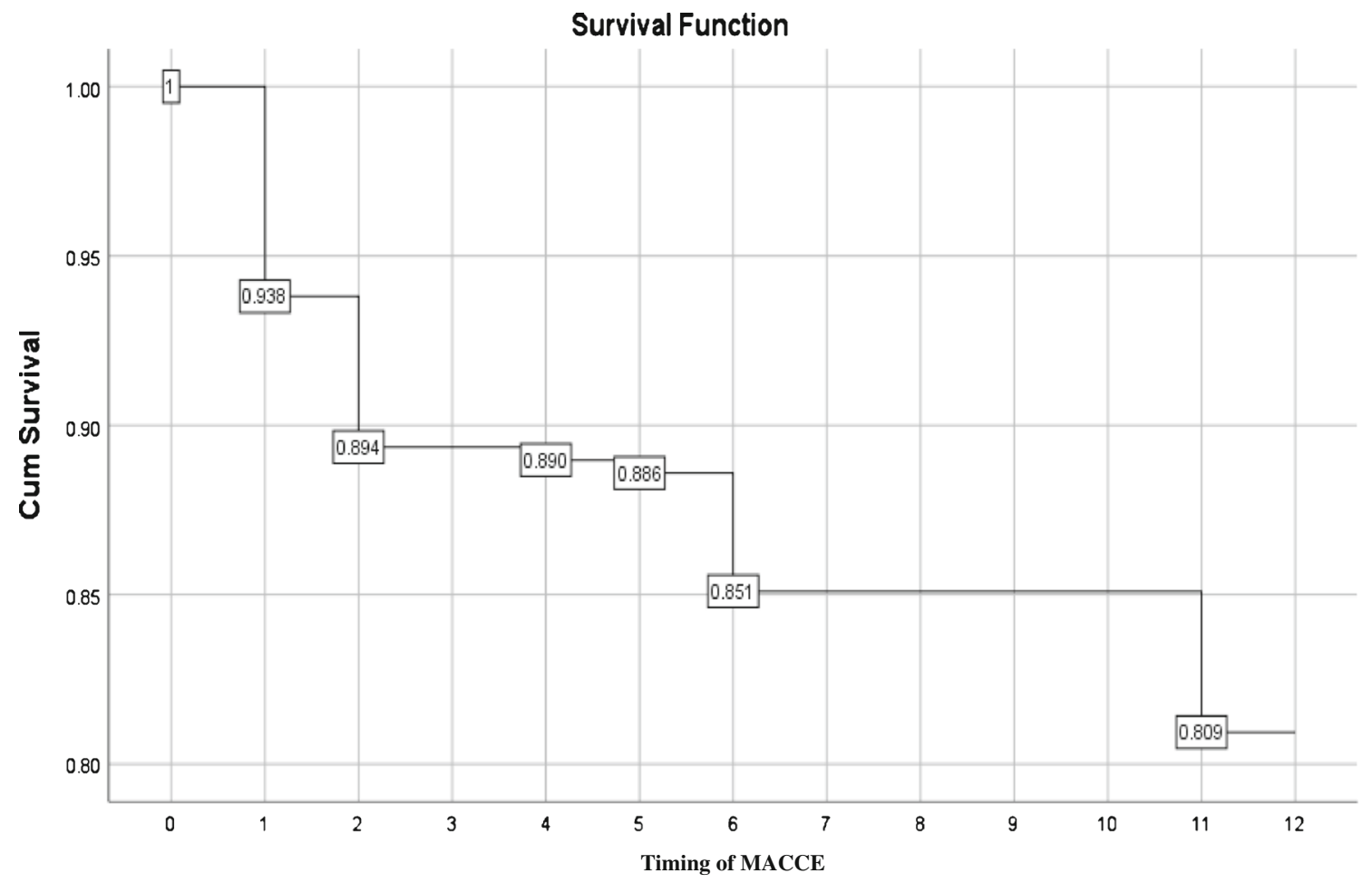

Fig. 2 Life table analysis of the MACCE occurrence rate among the study population

Out of the 277 patients studied, 18 were lost to follow-up and the remaining 259 patients were followed up for a minimum period of 10 years and a maximum period of 20 years.

The mean duration of follow-up was $142.83 \pm 56.38$ months. Kaplan-Meier analysis showed an overall survival time of 226.3 months [standard error (SE), $3.626]$ in the entire study population. The mean survival time in males was 227.5 months (SE, 4.736) and 206.3 months (SE, 5.118) in females, with no statistically significant difference between the two [Log rank

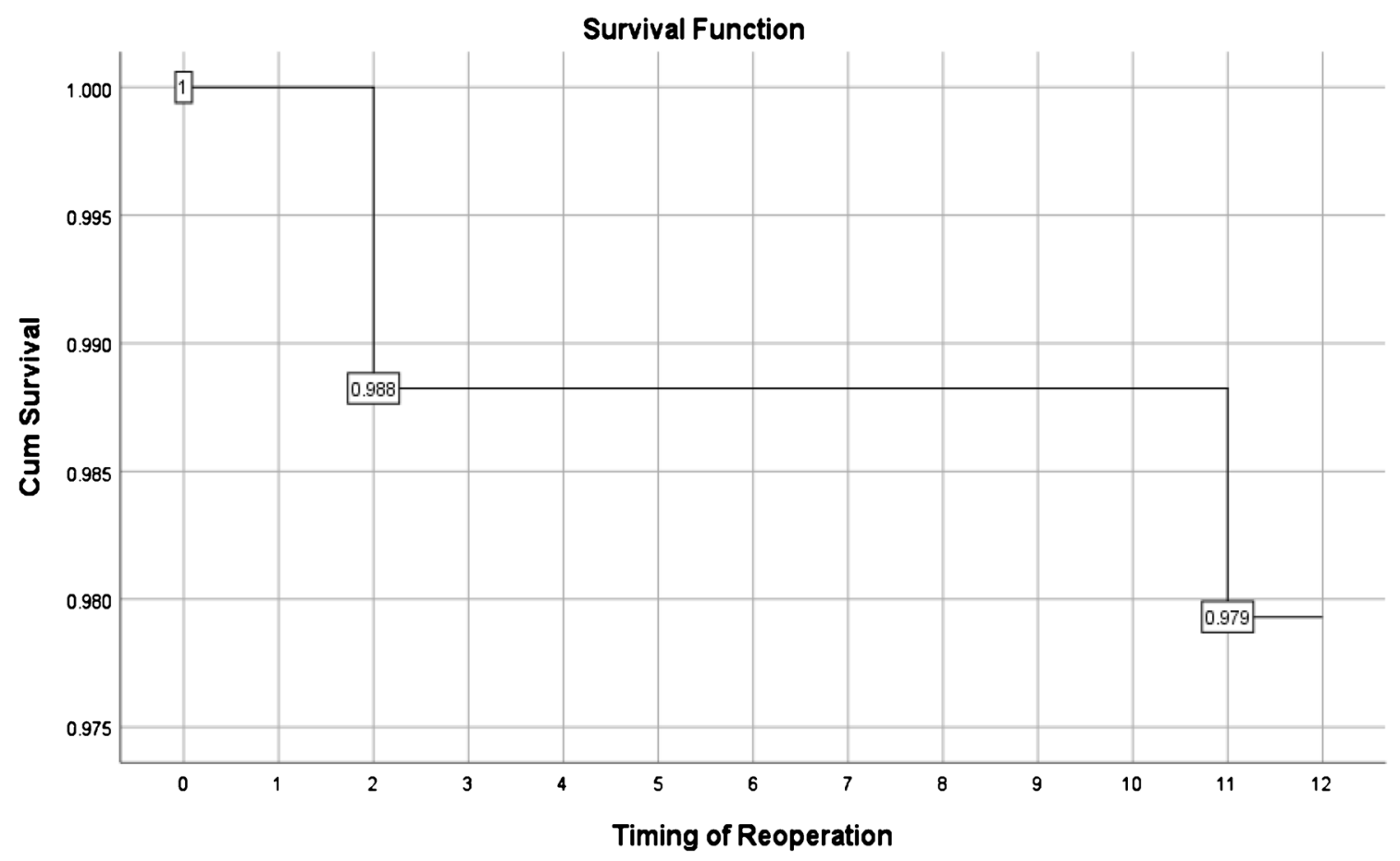

Fig. 3 Life table analysis of re-operation in the study population 
Fig. 4 Kaplan-Meier curves comparing the survival time between both genders
Survival Functions

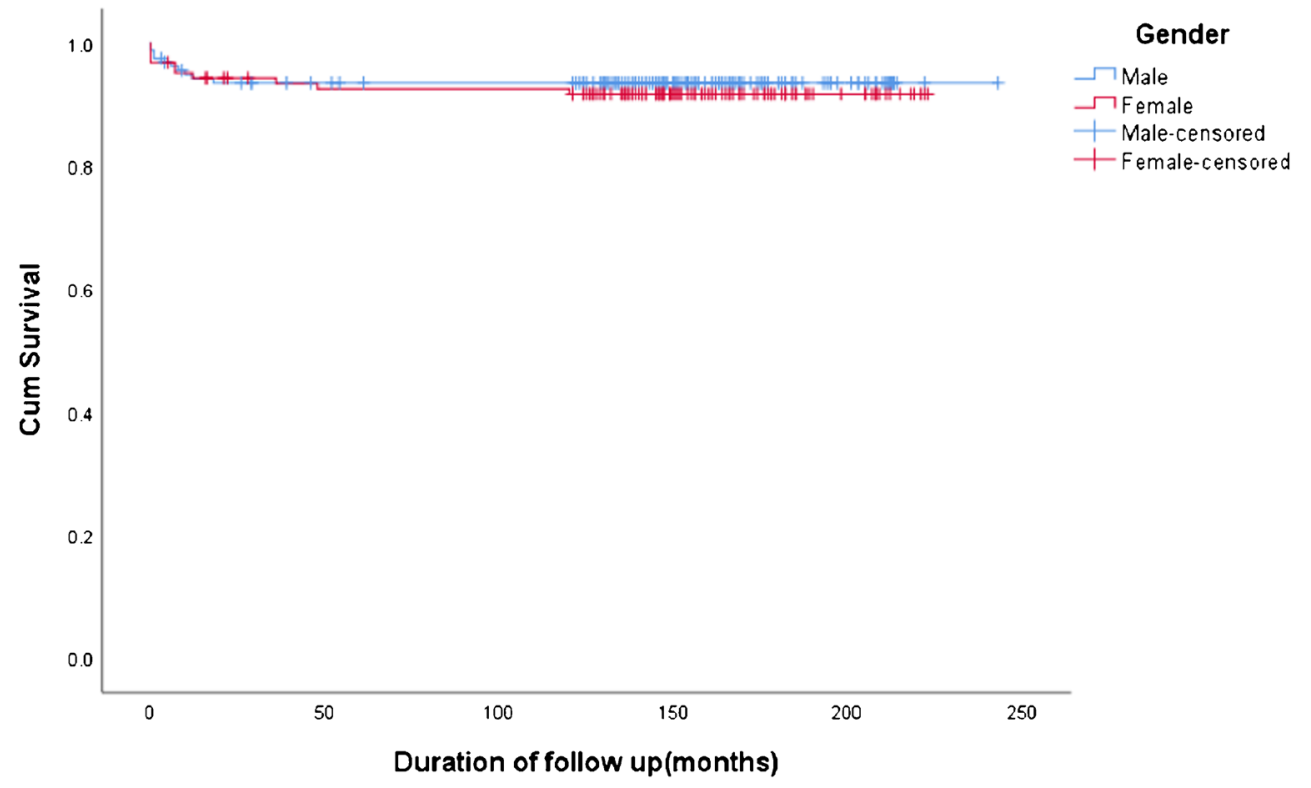

(Mantel-Cox) chi-square, 0.278; $p$ value 0.598] (Fig. 4, Kaplan-Meier curves comparing the survival time between both genders).

Univariate logistic regression analysis of the factors associated with mortality while combining tricuspid valve procedures with DVR revealed an association with an odds ratio of 4.5 ( $p$ value 0.005 ) (Table 3). Multivariate logistic regression analysis also showed an association with mortality when tricuspid valve procedures were combined with DVR, with an odds ratio of 5.25 ( $p$ value 0.003 ) (Table 4). Univariate logistic regression analysis of the factors associated with stroke did not reveal any association (Table 5). None of the other factors studied such as age, gender, rhythm, length of hospital stay, left ventricular (LV) ejection fraction and history of CMV and BMV had any relation to mortality or stroke with univariate and multivariate analyses.

\section{Discussion}

DVR has been associated with a higher operative mortality. The in-hospital mortality in this study was $2.5 \%$, and this is among one of the lowest reported for a DVR. Post-CPB myocardial dysfunction and low cardiac output syndrome (LCOS) were the common causes of death in the immediate postoperative period.

Talwar et al. reported an early mortality of $8.5 \%$ in the DVR group ( $n=293$ ) of their study comparing aortic valve replacement with mitral valve repair compared with combined AVR and MVR. The causes of early mortality were arrhythmia, bleeding and sepsis. They did not include patients who needed tricuspid valve repair. Also, theirs was a single operator-based study and majority of their patients belonged to NYHA functional class I and II [4]. Kim et al. studied 663 patients who underwent AVR combined with mitral valve
Table 3 Univariate logistic regression analysis of factors associated with overall mortality in the study population

\begin{tabular}{llrrr}
\hline Factor & Unadjusted odds ratio & 95\% CI of odds ratio & $p$ value \\
\cline { 2 - 4 } & & Lower & Upper \\
\hline Age & & 0.983 & 1.069 & 0.249 \\
Gender (baseline = male) & 1.025 & 0.521 & 3.218 & 0.578 \\
Rhythm (sinus) (baseline = atrial fibrillation) & 1.018 & 0.392 & 2.642 & 0.971 \\
Tricuspid procedures & 4.578 & 1.600 & 13.101 & 0.005 \\
Hospital stay & 1.065 & 0.994 & 1.140 & 0.074 \\
CMV & 1.886 & 0.507 & 7.015 & 0.344 \\
BMV & 3.929 & 0.993 & 15.548 & 0.051 \\
Ejection fraction & 0.979 & 0.934 & 1.027 & 0.387 \\
\hline
\end{tabular}

$B M V$ balloon mitral valvotomy, $C M V$ closed mitral valvotomy 
Table 4 Multivariate logistic regression analysis of factors associated with overall mortality in the study population

\begin{tabular}{lllrl}
\hline Factor & Adjusted odds ratio & \multicolumn{2}{l}{$95 \%$ CI of odds ratio } & \\
\cline { 3 - 4 } & & \multicolumn{1}{l}{ Lower } & Upper & \\
\hline Tricuspid procedures & 5.255 & 1.738 & 15.889 & 0.003 \\
CMV & 1.700 & 0.414 & 6.978 & 0.462 \\
BMV & 4.617 & 1.057 & 20.174 & 0.052 \\
\hline
\end{tabular}

$B M V$ balloon mitral valvotomy, $C M V$ closed mitral valvotomy surgery. They reported a very low early mortality of $1.9 \%$ in the DVR group of the study $(n=158)$. Two patients died of low cardiac output, and one patient had cerebral haemorrhage and succumbed. They included patients with all aetiologies and their study involved multiple operators. Despite these favourable early outcomes, they concluded DVR to be more hazardous than AVR with concomitant mitral valve repair based on long-term survival [5].

The other causes of in-hospital death in our study population were atrioventricular groove disruption (AVGD) and refractory medical bleeding in one patient each. The preoperative functional class of one of the patients who developed myocardial dysfunction was NYHA IV, and one of the patients who died from LCOS belonged to NYHA class III. AVGD is a rare complication post mitral valve surgery and is associated with annular calcification. Dobrilovic et al. reported an incidence of $0.42 \%$ of AVGD following mitral valve surgery [6]. Mortality rates with AVGD often approach $90 \%$.

The low in-hospital mortality observed in this study can be attributed to advancements in operative technique, myocardial protection and postoperative care along with better safety profiles of the prosthetic valves, since DVR first started in the 1960s. Cold blood cardioplegia with St Thomas II solution was employed for arresting the heart, and all patients were cooled to $30{ }^{\circ} \mathrm{C}$ after arresting the heart. The preoperative functional status of the patients included in the study may also have played a role in contributing to the low mortality rate.
$54.8 \%$ of the patients in our study had only NHYA class II symptoms preoperatively. Remadi et al. reported an operative mortality rate of $7.08 \%$ in their 22 -year follow-up of 254 patients who underwent DVR [2]. The percentage of patients who belonged to NYHA class III and IV was $66 \%$ in their study. The standard operative mortality reported by most of the studies on DVR varies between 5 and $12 \%$ [1-3, 7-11]. However, this huge difference in mortality cannot be completely attributed to this moderate difference in functional class alone. The late mortality rate in our study was $7.2 \%$, and there were three non-cardiac causes of death including GI bleeding and respiratory causes - acute respiratory distress syndrome and pneumonia.

The last patient in the study was followed up for a period of 10 years. We report a survival rate of $93.02 \%$ at 10 years. These values show a drastic improvement in survival compared to all the previous published studies on DVR patients [2]. The actuarial survival at 22 years as reported by Remadi et al. is $45 \%$. Their study included a follow-up of patients operated on between 1979 and 1989, and much has changed in operative techniques used in cardiac surgery, myocardial preservation and postoperative care since then. John et al. reported an actuarial survival of $85 \%$ at 10 years and $82 \%$ at 24 years in their follow-up of 456 patients between 1973 and 1997 [9].

The freedom from MACCE at 10 years is $85 \%$. Armenti et al. studied patients who were implanted with Starr Edward prosthesis and reported only a $40 \%$ freedom from thromboembolic and haemorrhagic complications at 15 years [12]. Our
Table 5 Univariate logistic regression analysis of factors associated with stroke in the study population

\begin{tabular}{lllll}
\hline Factor & Unadjusted odds ratio & \multicolumn{2}{c}{$95 \%$ CI of odds ratio } & \multirow{2}{*}{$p$ value } \\
\cline { 3 - 4 } & & Lower & Upper & \\
\hline Age & 1.023 & 0.986 & 1.061 & 0.222 \\
Gender (baseline = male) & 1.398 & 0.642 & 3.041 & 0.399 \\
Rhythm (sinus) (baseline = atrial fibrillation) & 1.528 & 0.646 & 3.614 & 0.334 \\
Tricuspid procedures & 1.724 & 0.540 & 5.505 & 0.358 \\
Hospital stay & 1.052 & 0.985 & 1.125 & 0.132 \\
CMV & 0.268 & 0.035 & 2.059 & 0.206 \\
BMV & 0.000 & - & - & 0.999 \\
Ejection fraction & 1.012 & 0.972 & 1.054 & 0.551 \\
\hline
\end{tabular}

$B M V$ balloon mitral valvotomy, $C M V$ closed mitral valvotomy 
Table 6 Comparison of long-term survival rates in various studies

\begin{tabular}{|c|c|c|c|c|c|}
\hline $\begin{array}{l}\text { Author, } \\
\text { journal, } \\
\text { year, country }\end{array}$ & $\begin{array}{l}\text { Number of } \\
\text { patients }\end{array}$ & Aetiology & & $\begin{array}{l}\text { Results and } \\
\text { late outcome }\end{array}$ & Comments \\
\hline \multirow[t]{2}{*}{$\begin{array}{l}\text { Coyan et al, } \\
\text { Journal of } \\
\text { Cardiac } \\
\text { Surgery, } \\
2018, \\
\text { USA }\end{array}$} & $\begin{array}{r}\text { DVR group } \\
\quad(n=177)\end{array}$ & $\begin{array}{c}\text { Aortic } \\
\text { Rheumatic- } \\
15.8 \% \\
\text { Degenerative- } \\
53.1 \% \\
\text { Endocarditis- } \\
7.3 \%\end{array}$ & $\begin{array}{l}\text { Mitral } \\
\text { Rheumatic- } \\
37.5 \% \\
\text { Degenerative } \\
57.6 \% \\
\text { Endocarditis- } \\
\quad 7.3 \%\end{array}$ & $\begin{array}{l}5 \text {-year mortality in the } \\
\text { DVR group was } 37.8 \%\end{array}$ & \multirow[t]{2}{*}{ Majority of the patients had degenerative aetiology. } \\
\hline & $\begin{array}{l}\text { AVR plus } \\
\text { MVr } \\
\text { group } \\
(n=247)\end{array}$ & $\begin{array}{c}\text { Aortic } \\
\text { Rheumatic- } \\
2.4 \% \\
\text { Degenerative- } \\
63.2 \% \\
\text { Endocarditis- } \\
8.5 \%\end{array}$ & $\begin{array}{l}\text { Mitral } \\
\text { Rheumatic- } \\
1.2 \% \\
\text { Degenerative- } \\
\quad 61.9 \% \\
\text { Endocarditis- } \\
\quad 8.1 \%\end{array}$ & $\begin{array}{l}\text { 5-year mortality in AVR } \\
\text { plus MVr group was } \\
35.1 \%\end{array}$ & \\
\hline $\begin{array}{l}\text { Kim et al., } \\
\text { ICVTS, 2014, } \\
\text { South Korea }\end{array}$ & $\begin{array}{l}\text { DVR group } \\
\quad(n=158) \\
\text { AVR plus } \\
\quad \text { MVr } \\
\text { group } \\
(n=95)\end{array}$ & \multicolumn{2}{|c|}{$\begin{array}{l}\text { Rheumatic-50.8\% } \\
\text { Degenerative-26.1\% } \\
\text { Endocarditis-23.1\% } \\
\text { Rheumatic- } 37.5 \% \\
\text { Degenerative- } 41.4 \% \\
\text { Endocarditis- } 21.1 \%\end{array}$} & $\begin{array}{l}\text { Overall survival at } \\
10 \text { years was } \\
77.2 \pm 4.4 \% \\
\text { Overall survival at } \\
10 \text { years was } \\
73.0 \pm 6.4 \%\end{array}$ & $\begin{array}{c}\text { They studied mitral valve repair versus replacement for } \\
\text { moderate-to-severe mitral regurgitation in patients } \\
\text { undergoing concomitant AVR. }\end{array}$ \\
\hline $\begin{array}{l}\text { Talwar et al, } \\
\text { The Annals of } \\
\text { Thoracic } \\
\text { Surgery, } \\
2007, \\
\text { India }\end{array}$ & $\begin{array}{l}\text { DVR group } \\
\quad(n=293) \\
\text { AVR plus } \\
\quad \mathrm{MVr} \\
\text { group } \\
(n=76)\end{array}$ & \multicolumn{2}{|c|}{ Rheumatic-100\% } & $\begin{array}{l}\text { Actuarial survival was } \\
81.60 \pm 2.4 \% \\
\text { Actuarial survival was } \\
90.5 \pm 3.4 \%\end{array}$ & Aetiology was purely rheumatic in origin. \\
\hline $\begin{array}{l}\text { Kuwaki et al, } \\
\text { The Annals of } \\
\quad \text { Thoracic }\end{array}$ & $\begin{array}{l}\text { DVR group } \\
\quad(n=81)\end{array}$ & \multicolumn{2}{|c|}{ Rheumatic-100\% } & $\begin{array}{l}\text { Rates of actuarial freedom } \\
\text { from cardiac-related } \\
\text { death } 75.9 \% \text { at } 12 \text { years }\end{array}$ & \multirow{2}{*}{$\begin{array}{c}\text { Aetiology was exclusively rheumatic. Even though they } \\
\text { did not find any significant difference in mortality } \\
\text { between the two groups, the reoperation rate was } \\
\text { high in the mitral valve repair group. }\end{array}$} \\
\hline $\begin{array}{l}\text { Surgery, } \\
2007, \\
\text { Japan }\end{array}$ & $\begin{array}{l}\text { AVR plus } \\
\text { MVr } \\
\text { group } \\
(n=47)\end{array}$ & \multicolumn{2}{|c|}{ Rheumatic-100\% } & $\begin{array}{l}\text { Rates of actuarial freedom } \\
\text { from cardiac-related } \\
\text { death } 81.4 \% \text { at } 12 \text { years }\end{array}$ & \\
\hline $\begin{array}{l}\text { McGonigle } \\
\text { et al, } \\
\text { Journal of }\end{array}$ & $\begin{array}{r}\text { DVR group } \\
\quad(n=273)\end{array}$ & \multicolumn{2}{|c|}{$\begin{array}{l}\text { Rheumatic- }-77.3 \% \\
\text { Degenerative- } 20.5 \% \\
\text { Endocarditis- } 0.7 \%\end{array}$} & $\begin{array}{l}\text { Fifteen-year survival was } \\
\quad 44 \%\end{array}$ & \multirow[t]{2}{*}{$\begin{array}{c}\text { More than } 70 \% \text { of the patients in both the groups had } \\
\text { rheumatic aetiology. }\end{array}$} \\
\hline $\begin{array}{l}\text { Cardiothora- } \\
\text { cic Surgery, } \\
2007, \\
\text { UK }\end{array}$ & $\begin{array}{l}\text { AVR plus } \\
\text { MVr } \\
\text { group } \\
(n=43)\end{array}$ & \multicolumn{2}{|c|}{$\begin{array}{l}\text { Rheumatic- } 72.1 \% \\
\text { Degenerative }-18.6 \% \\
\text { Endocarditis-7.0\% }\end{array}$} & $\begin{array}{l}\text { Fifteen-year survival was } \\
57 \%\end{array}$ & \\
\hline
\end{tabular}

$D V R$ double valve replacement, $A V R$ aortic valve replacement, $M V r$ mitral valve repair

study included patients with four kinds of mechanical prosthesis including Chitra heart valve prosthesis and a bioprosthetic valve. We maintained a target prothrombin time-international normalized ratio (PT INR) of 2.5 to 3.5 in all patients undergoing DVR with mechanical prosthesis. Patients who underwent valve replacement with bioprosthetic valves (two patients) received anticoagulation with vitamin $\mathrm{K}$ antagonist for three months following surgery. There were three instances of valve thrombosis (two at mitral position and one at aortic position), one incident of intracranial bleed and a case of GI bleed with this anticoagulation regimen.
Talwar et al. reported a very high rate (21\%) of thromboembolic complications in the DVR group of their study. They could not point out a specific cause to this phenomenon and termed most of the events as minor. However, eighteen of the sixty-two patients who developed these complications were in atrial fibrillation. They followed an anticoagulation regimen targeting INR of 2.5 to 3.5 [4]. Saurav et al. conducted a metaanalysis of all the observational studies comparing mitral valve repair vs replacement along with concomitant AVR. They analysed three studies which included rheumatic patients exclusively and found that risk of thromboembolism 
was lower in patients with RHD undergoing mitral valve (MV) repair compared with replacement [13]. We attribute the low rate of thromboembolic events in our study to the good compliance to anticoagulation due to patient education prior to surgery and discharge and meticulous follow-up.

The number of patients who had to be re-operated on at the end of 10 years was five, and the freedom from re-operation at 10 years was $98 \%$. The causes of re-operation were prosthetic valve thrombosis-Medtronic Hall valve (Medtronic, Inc., Minneapolis, MN) in the aortic and Starr-Edwards valve (Edwards Lifesciences, Irvine, CA) in the mitral position, and prosthetic valve endocarditis which required redo DVR and paravalvular regurgitation-Chitra heart valve prosthesis (TTK CHVP, TTK Healthcare Limited, Chennai, Tamil Nadu).

Kaplan-Maier analysis showed a cumulative survival rate of 226 months (18 years) post-DVR. Literature has shown that the survival rate in female patients is lower post cardiac surgery, but the mean survival rate difference between men and women was not statistically significant in our cohort.

The functional status improved significantly post DVR with $71 \%$ patients reporting NYHA class I functional status.

Coyan et al. in their study of 424 patients compared the outcomes of MVR with repair during concomitant AVR. They reported a 5-year mortality of $37.8 \%$ for patients in the DVR group. In their study population, $15.8 \%$ (aortic) to $37.5 \%$ (mitral) patients had rheumatic aetiology. Majority (53 to 57\%) of the patients had degenerative valve disease, and the mean age was 68.8 \pm 11.8 years [14]. In our study, we included only patients with RHD who usually present earlier, and this is reflected in the lower mean age of patients in our study population (Table 6).

Patients with RHD thus have a better freedom from mortality after DVR as they present earlier, compared to those patients with degenerative valve disease who become symptomatic at a later part of their life.

Kim et al. reported an overall survival of $77.2 \pm 4.4 \%$ in the DVR group at 10 years follow-up [5]. Their study included patients with mixed aetiologies out of which RHD patients accounted for $50.8 \%$ of the population. Talwar et al. in their study of 369 patients with RHD compared results of AVR and mitral valve repair with combined AVR and MVR. They reported an actuarial survival of $81.60 \% \pm 2.4 \%$ in the DVR group at 5 years [4].

Kuwaki et al. reported an actuarial freedom from cardiacrelated death of $75.9 \%$ at 12 years in the DVR group of their study involving 128 RHD patients. Eighty-one among them underwent DVR, while 47 patients underwent mitral valve repair along with AVR [15]. McGonigle et al. reported a fifteen-year survival of $44 \%$ for DVR group $(n=273)$ in their study of 316 patients. More than $70 \%$ patients in the study had rheumatic aetiology [16].

The aforementioned studies predominantly or entirely included patients with rheumatic aetiology, whose long-term survival rate varied between 44 and $81 \%$. In our study, we found the 10-year survival rate to be $93.02 \%$ and such a high survival post DVR has not been reported. We attribute this improved survival rate to the lower mean age of the patients at the time of surgery, preserved functional class and surgical and myocardial preservation techniques.

Gupta et al. in their study of 150 patients who underwent DVR found female sex, advanced age, higher NYHA class and poor LV function to be associated with poor outcomes [3]. Combining tricuspid valve intervention with DVR was found to have an association with mortality in our study. The other factors studied such as age, gender, rhythm, length of hospital stay, LV ejection fraction, history of CMV and BMV did not have any relation to mortality or stroke when analysed using univariate and multivariate logistical regression.

\section{Conclusion}

The operative mortality and morbidity for DVR have significantly reduced with improvement in operative techniques, myocardial preservation and postoperative care. Patients can have an improved quality of functional status following surgery, with good rates of freedom from re-operation and MACCE.

\section{Limitations}

This is a retrospective study and has its inherent limitations. It was a single-centre-based study. A multi-centre-based study would validate the findings better. A prospective study would have helped us study details of myocardial protection and other factors contributing to low operative mortality well.

Funding Authors declare that there was no funding involved.

\section{Compliance with ethical standards}

Conflict of interest The authors declare that they have no conflict of interests.

Ethical committee approval Institutional ethics committee clearance has been obtained. IEC no-SCT/IEC/1380/JUNE-2019 dated 22/08/2019.

Informed consent As this is a retrospective study design based on hospital records, the need to obtain informed consent has been waived off.

Statement of human and animal rights There was no infringement of human or animal rights in this study.

\section{References}

1. Teoh KH, Christakis GT, Weisel RD, et al. The determinants of mortality and morbidity after multiple-valve operations. Ann Thorac Surg. 1987;43:353-60. 
2. Remadi JP, Baron O, Tribouilloy C, et al. Bivalvular mechanical mitral-aortic valve replacement in 254 patients: long-term resultsa 22-year follow-up. Ann Thorac Surg. 2003;76:487-92.

3. Gupta M, Shoeb M, Mishra PK, Dhar S, Prasad J. Factors influencing the outcome of double valve replacement surgery. Int Surg J. 2017;4:1913-7.

4. Talwar S, Mathur A, Choudhary SK, Singh R, Kumar AS. Aortic valve replacement with mitral valve repair compared with combined aortic and mitral valve replacement. Ann Thorac Surg. 2007;84:1219-25.

5. Kim GS, Kim JB, Han S, et al. Mitral valve repair versus replacement for moderate-to-severe mitral regurgitation in patients undergoing concomitant aortic valve replacement. Interact Cardiovasc Thorac Surg. 2014;18:73-9. https://doi.org/10.1093/icvts/ivt402.

6. Dobrilovic N, Raman J, Fingleton JG, Maslow A, Singh AK. Longterm outcomes of external repair as a rescue operation for atrioventricular groove disruption. Ann Thorac Surg. 2017;103:491-6.

7. Arom KV, Nicoloff DM, Kersten TE, Northrup WF III, Lindsay WG, Emery RW. Ten-year follow-up study of patients who had double valve replacement with the St. Jude Medical prosthesis. J Thorac Cardiovasc Surg. 1989;98:1008-15.

8. Kratz JM, Crawford FA Jr, Sade RM, Crumbley AJ, Stroud MR. St. Jude prosthesis for aortic and mitral valve replacement: a ten-year experience. Ann Thorac Surg. 1993;56:462-8.

9. John S, Ravikumar E, John CN, Bashi VV. 25-year experience with 456 combined mitral and aortic valve replacement for rheumatic heart disease. Ann Thorac Surg. 2000;69:1167-72.
10. Kinsley RH, Antunes MJ, Colsen PR. St. Jude Medical Valve Replacement. An evaluation of valve performance. J Thorac Cardiovasc Surg. 1986;92:349-60.

11. Turina J, Stark T, Seifert B, Turina M. Predictors of the long term outcome after combined aortic and mitral valve surgery. Circulation. 1999;100:II-48-53.

12. Armenti F, Stephenson LW, Edmunds LH Jr. Simultaneous implantation of St. Jude medical aortic and mitral prostheses. J Thorac Cardiovasc Surg. 1987;94:733-9.

13. Saurav A, Alla VM, Kaushik M, Hunter CC, Mooss AV. Outcomes of mitral valve repair compared with replacement in patients undergoing concomitant aortic valve surgery: a meta-analysis of observational studies. Eur J Cardiothorac Surg. 2015;48:347-53. https:// doi.org/10.1093/ejcts/ezu421.

14. Coyan GN, Aranda-Michel E, Sultan I, et al. Outcomes of mitral valve surgery during concomitant aortic valve replacement. J Card Surg. 2018;33:706-15. https://doi.org/10.1111/jocs.13824.

15. Kuwaki K, Kawaharada N, Morishita K, et al. Mitral valve repair versus replacement in simultaneous mitral and aortic valve surgery for rheumatic disease. Ann Thorac Surg. 2007;83:558-63.

16. McGonigle NC, Jones JM, Sidhu P, MacGowan SW. Concomitant mitral valve surgery with aortic valve replacement: a 21 -year experience with a single mechanical prosthesis. J Cardiothorac Surg. 2007;2:24.

Publisher's note Springer Nature remains neutral with regard to jurisdictional claims in published maps and institutional affiliations. 